\title{
THIN ICE AREA EXTRACTION IN THE SEASONAL SEA ICE ZONES OF THE NORTHERN HEMISPHERE USING ASMR2 DATA
}

\author{
K. Cho ${ }^{1 *}$, K. Miyao ${ }^{1}$, K. Naoki ${ }^{1}$ \\ 'Tokai University, 2-28-4, Tomigaya, Shibuya-ku, Tokyo, Japan, kohei.cho@tokai-u.jp
}

Commission III, WG III/2

KEY WORDS: sea ice, passive microwave radiometer, global warming, GCOM-W

\begin{abstract}
:
Sea ice has an important role of reflecting the solar radiation back into space. In addition, the heat flux of ice in thin ice areas is strongly affected by the ice thickness difference. Therefore, ice thickness is one of the most important parameters of sea ice. In our previous study, the authors have developed a thin ice area extraction algorithm using passive microwave radiometer AMSR2 for the Sea of Okhotsk. The basic idea of the algorithm is to use the brightness temperature scatter plots of AMSR2 19GHz polarization difference (V-H) vs $19 \mathrm{GHz}$ V polarization. The algorithm was also applicable to the Bering Sea, and could extract most of the thin ice areas. However, two problems have become clear. One was that some the thin ice areas were not well extracted, and the other was that some of the consolidated ice were mis-extracted as thin ice areas. In this study, the authors have improved the thin ice area extraction algorithm to solve these problems. By adjusting the parameters of the algorithm applied to the brightness temperature scatter plots of AMSR2 $19 \mathrm{GHz}$ polarization difference $(\mathrm{V}-\mathrm{H})$ vs $19 \mathrm{GHz}$ V polarization, most of the thin ice areas were also well extracted in the Bering Sea. The authors also introduced an equation using the brightness temperatures difference of $89 \mathrm{GHz}$ vertical and horizontal polarization to reject the thin ice area misextracted over consolidated ice. By applying the above two methods to AMSR2 data, most of the thin ice areas in the Bering Sea were well extracted. The algorithm was also applied to the Gulf of St. Lawrence with good result. The thin ice area extracted data are planed to be approved by JAXA as a AMSR 2 research product.
\end{abstract}

\section{INTRODUCTION}

Since 1978, passive microwave radiometers, including AMSR2 onboard GCOM-W satellite, have been continuously observing the earth for 40 years. The long-term sea ice extent derived from the passive microwave observation showed clear decline trend of the Arctic sea ice cover (Comiso, 2012, JAXA, 2012, NSIDC, 2018 etc.). The result is referred as an evidence of global warming in the Fifth Assessment Report of IPCC (2014). Usually, sea ice extent is calculated from sea ice concentration derived from brightness temperatures measured by passive microwave radiometers. Ice concentration is the most fundamental parameter of sea ice which can be calculated from brightness temperatures measured by passive microwave radiometers. There are number of sea ice concentration algorithms including NASA Team Algorithm (Cavarieli et al., 1984), Bootstrap Algorithm (Comiso, 1995) and ASI Algorithm (Svendsen et al. .1987).

Since the heat flux of ice is strongly affected by the ice thickness (Maykut, 1978), ice thickness is another important parameter of sea ice. However, the sea ice thickness information cannot be estimated from the sea ice concentration data. Studies on estimating ice thickness from the brightness temperature data acquired from passive microwave radiometers onboard satellites have been done in the past including those of Tateyama et al. (2002), Martin et al. (2005), and Tamura et al. (2007). However, the detailed validation of the accuracy of the estimated sea ice thickness is still on the way. Estimating ice thickness from passive microwave radiometer is not easy. The authors have been developing a method to extract thin ice area using brightness temperature scatter plots of AMSR2 $19 \mathrm{GHz}$ polarization difference $(\mathrm{V}-\mathrm{H})$ vs $19 \mathrm{GHz} \mathrm{V}$ polarization for the Sea of Okhotsk (Cho et. Al, 2012, 2014, 2015). In this study, "thin ice" is defined as the ice which thickness is around less than $30 \mathrm{~cm}$. Cho et al. $(2011,2012)$ has done detailed studies on comparing the in situ ice thickness measurement result with the data observed by optical sensors such as RSI on FORMOSAT-2 and MODIS on Aqua/Terra. The result suggested that if the ice thickness is less than $30 \mathrm{~cm}$, under the less snow cover condition, the ice thickness difference can be detected with optical sensors such as RSI and MODIS. In this study, the MODIS images are used as the reference of identifying thin ice areas, the possibility of extract thin ice area with AMSR2 data are validated by comparing with the MODIS images. The result of applying the thin ice area extraction algorithm, hereafter referred to as the Thin Ice Algorithm, to AMSR2 data in the seasonal sea ice zones of the northern hemisphere including the Sea of Okhotsk, Bering Sea, and Gulf of St. Lawremce are presented in this paper.

\section{TEST SITES}

Figure 1 show the map of the test sites analyzed in this study which are the Sea of Okhotsk, the Bering sea and the Gulf of Saint Lawrence. All three are seasonal sea ice zones of the northern hemisphere. The Sea of Okhotsk is located at the north side of Hokkaido, Japan, surrounded by the Island of Sakhalin and eastern Siberian coast, Kamchatka Peninsula and Kuril Islands. The sea is one of the most southern seasonal sea ice zones in the northern hemisphere, and many thin

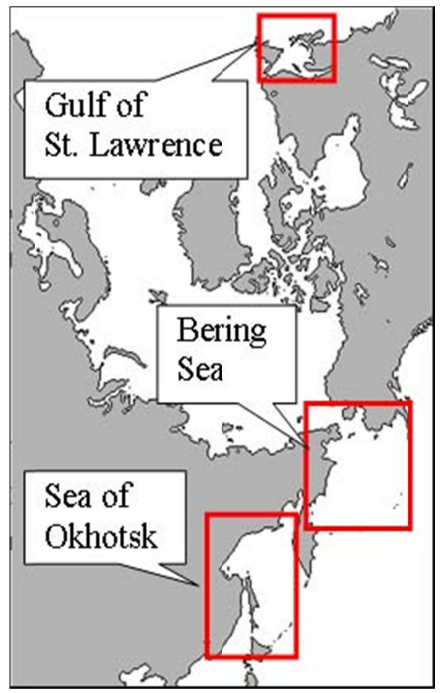

*Kohei Cho, Tokai University Research \& Information Center, 2-28-4, Tomigaya, Shibuya-ku, Tokyo151-0063, Japan 
ice areas can be found in the sea. The Bering Sea is located in the northernmost part of the Pacific Ocean, which is surrounded by the Siberia, the Kamchatka Peninsula, the Alaska Peninsula and the Aleutian Islands. The Bering Sea is connected to Arctic Ocean by the Bering Strait. The Gulf of St. Lawrence is a kind of inland sea located in eastern Canada. It is the outlet of North America's Great Lakes via the Saint Lawrence River into the Atlantic Ocean.

\section{ANALYZED DATA}

The brightness temperature data acquired from passive microwave radiometer AMSR2 onboard GCOM-W satellite were used in this study. GCOM-W was launched by JAXA in 2012 and AMSR2 has been observing the earth for over 6 years. Table 1 shows the specifications of AMSR2. The ice concentration data derived from AMSR2 data using Bootstrap Algorithm (Comiso, 2009) were also used in this study. In order to identify thin ice areas, data collected by optical sensor MODIS onboard Aqua satellite were used as reference. Table 3 show the specifications of MODIS. As for MODIS, only the Band 1 and 2 which have the highest spatial resolution of $250 \mathrm{~m}$ were used in this study. Under the cloud free condition, detailed distribution of sea ice can be observed from MODIS images. Since Aqua and GCOM-W are in the same orbital "track" under the frame work of the NASA's A-Train (NASA, 2012), the constellation of satellites, MODIS onboard Aqua observed the same area four minutes after the observation of AMSR2 onboard GCOM-W. Therefore, MODIS data is one of the most effective validation data for AMSR2 data.

Table 1. Specifications of AMSR2

\begin{tabular}{|c|c|c|c|}
\hline $\begin{array}{c}\text { Frequency } \\
\text { (polarization) }\end{array}$ & IFOV & Swath & $\begin{array}{l}\text { Incident } \\
\text { angle }\end{array}$ \\
\hline $7 \mathrm{GHzV}, \mathrm{H})$ & $35 \times 62 \mathrm{~km}$ & \multirow{6}{*}{$\begin{array}{c}1450 \\
\mathrm{~km}\end{array}$} & \multirow{6}{*}{$55 \mathrm{deg}$} \\
\hline $11 \mathrm{GHz}(\mathrm{V}, \mathrm{H})$ & $24 \times 42 \mathrm{~km}$ & & \\
\hline $19 \mathrm{GHz}(\mathrm{V}, \mathrm{H})$ & $14 \times 22 \mathrm{~km}$ & & \\
\hline $24 \mathrm{GHz}(\mathrm{V}, \mathrm{H})$ & $15 \times 26 \mathrm{~km}$ & & \\
\hline $36 \mathrm{GHz}(\mathrm{V}, \mathrm{H})$ & $7 \times 12 \mathrm{~km}$ & & \\
\hline $89 \mathrm{GHz}(\mathrm{V}, \mathrm{H})$ & $3 \times 5 \mathrm{~km}$ & & \\
\hline
\end{tabular}

Table 2. Specifications of MODIS

\begin{tabular}{|c|c|c|c|}
\hline Band & Wavelength & IFOV & Swath \\
\hline 1 & $0.620-0.670 \mu \mathrm{m}$ & \multirow{2}{*}{$250 \mathrm{~m}$} & \multirow{2}{*}{$2330 \mathrm{~km}$} \\
\hline 2 & $0.841-0.876 \mu \mathrm{m}$ & & \\
\hline
\end{tabular}

\section{RESEARCH METHOD}

\subsection{Sample Area selection}

Figure 2 show the comparison of simultaneously collected AMSR2 ice concentration image and MODIS image of the Sea of Okhotsk taken on February 27, 2013. The clear distribution of sea ice can be identified from the AMSR2 ice concentration image as shown on Figure 2(a).

However, it is difficult to identify ice thickness differences or thin ice areas from the image. On the other hand, more detailed sea ice distributions can be observed in the color composite image of MODIS(Band 1 to blue and red, Band 2 to green) as shown on Figure 2(b). In our thin ice algorithm, we first select sample areas of thin sea ice, big ice floe, open water and mixed sea ice are selected in this study as sown on Figure 2 and 3.

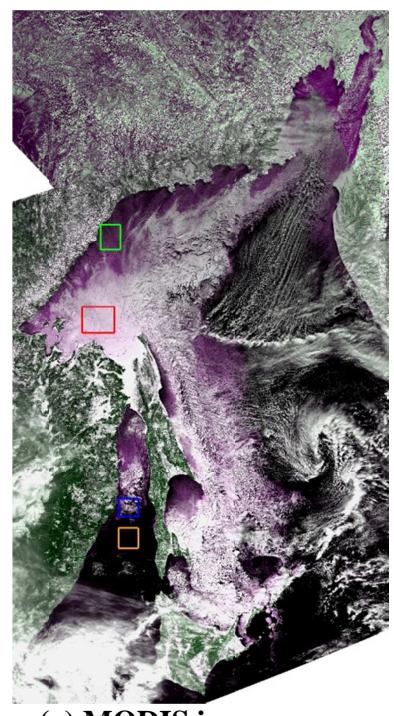

(a) MODIS image

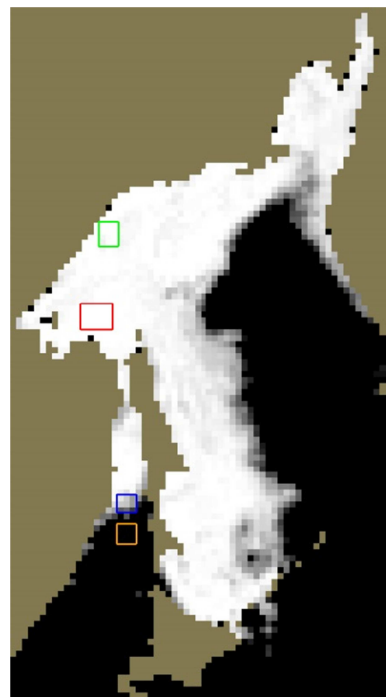

(b) AMSR2 ice concentration
Figure 2. Comparison of AMSR2 and MODIS images. (Sea of Okhotsk, February 27,2013)

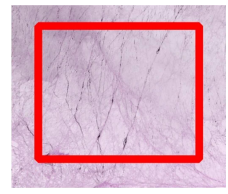

(a)Big ice floe

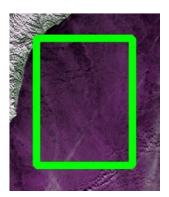

(b)Thin ice (c)Mixed ice

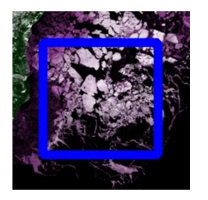

(d)

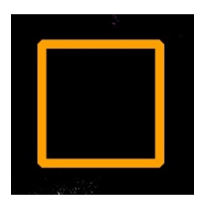

(d)Open water
Figure 3. Sample area of different ice types extracted from MODIS image (Sea of Okhotsk, Feb. 27, 2013)

\subsection{Thin Ice Algorithm}

Figure 4 shows the scatter plot of AMSR2 $19 \mathrm{GHz} \mathrm{V}$ versus $19 \mathrm{GHz}(\mathrm{V}-\mathrm{H})$ of the Sea of Okhotsk observed on February27, 2013. In this scatter plot, $\boldsymbol{\Delta}$ represents thin ice and $\square$ represents big ice floe. The basic idea of our Thin Ice Algorithm is to extract the thin ice area by applying the following two equations to the brightness temperatures (Tb) of $19 \mathrm{GHz}$ Vertical(V) and Horizontal(H) polarization of AMSR2.

\section{(Tb19GHzV) $>$ T1}

$(\mathrm{Tb} 19 \mathrm{GHzV}-\mathrm{Tb} 19 \mathrm{GHzH})>-\mathrm{Tb} 19 \mathrm{GHzV}+\mathrm{T} 2$

where Tb19GHzH: Tb of AMSR2 19GHz H polarization Tb19GHzV: Tb of AMSR2 19GHz V-polarization T1, T2: parameters adjusted to particular sea ice zone.

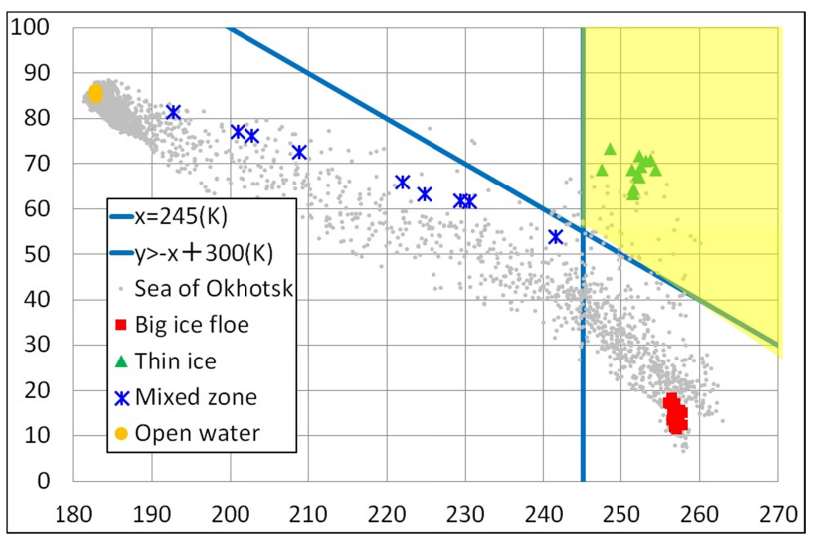

Figure 4. Scatter plots of (19GHzV - 19GHzH) Vs 19GHzV Polarization (Sea of Okhotsk, Feb. 27, 2013) 
It is impossible to identify ice thickness difference in the low ice concentration areas. The equation (1) is used to extract sea ice area with $80 \%$ or higher sea ice concentration. In other words, our target is thin ice area which concentration is higher than $80 \% /$ The microwave brightness temperature of water is much lower in $\mathrm{H}$ polarization than in that of $\mathrm{V}$ polarization. Since thin ice areas are rather wet, the microwave brightness temperature of thin ice areas become much lower in $\mathrm{H}$ polarization than in that of $\mathrm{V}$ polarization. On the other hand, the microwave brightness temperature of consolidated ice does not show big difference between $\mathrm{V}$ and $\mathrm{H}$ polarization. Considering these characteristics, the authors have introduced equation (2) for extracting thin ice area.

\section{EXTRACTED RESULT}

\subsection{Sea of Okhotsk}

Firstly, the authors have applied the Thin Ice Algorithm to AMSR2 data of the Sea of Okhotsk. Figure 5(a) shows the AMSR2 sea ice concentration image of February 27, 2013. The cyan areas in the image show the "thin ice areas" extracted using AMSR2 data using equations (1) and (2). T1=245K and $\mathrm{T} 2=300 \mathrm{~K}$ are specified for the Sea of Okhotsk. The extracted areas were overlaid on the simultaneously collected MODIS image for evaluation as shown on Figure 5 (b). It shows that not all but most of the thin ice areas which are appearing in dark purple in the MODIS image are extracted with the proposed method.

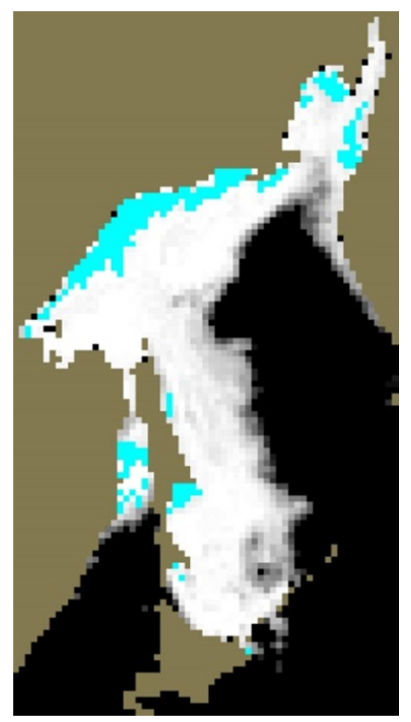

(a)AMSR2 image

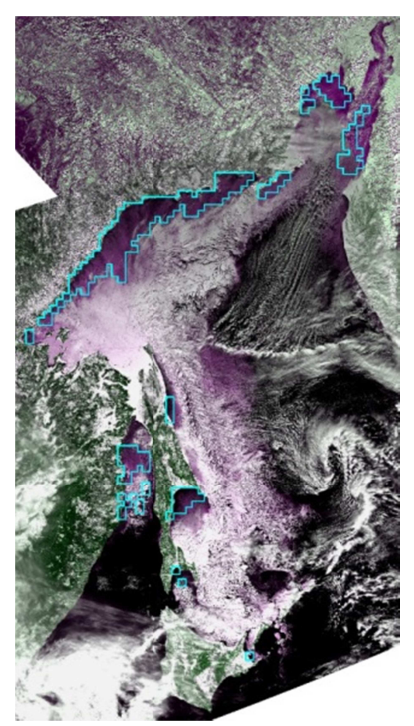

(b) MODIS image
Figure 5. Thin ice area extraction result (Cyan: extracted area) (Sea of Okhotsk, Feb. 27, 2013)

\subsection{Bering Sea}

The authors have applied the Thin Ice Algorithm to several scenes of AMSR2 data for the Bering Sea observed on March 19, 2016. Figure 6 shows the scatter plot of AMSR2 19GHz V versus $19 \mathrm{GHz}(\mathrm{V}-\mathrm{H})$ of the Bering Sea observed on March 19, 2016. The blue meshed area represents the area to be extracted as thin ice area with equation (1) and (2). It is clear that the unextracted sea ice areas $(\square)$ are distributed outside of the blue meshed area. Therefore, the authors have changes parameter $\mathrm{T} 1$ of equation (1) from $245 \mathrm{~K}$ to $235 \mathrm{~K}$. No change to the parameter $\mathrm{T} 2=300 \mathrm{~K}$. In order to reject the effect of misextracting some of the big ice floe as thin ice areas, the authors have added the following equation to the algorithm( see .Miyao et al, 2018)

$$
(\mathrm{Tb} 89 \mathrm{GHzV}-\mathrm{Tb} 89 \mathrm{GHzH})>20 \mathrm{~K}
$$

where Tb89GHzV: Tb of AMSR2 89GHz V polarization

Tb89GHzH: Tb of AMSR2 89GHz H polarization

Figure 7 show the extracted thin ice areas overlaid on the AMSR2 sea ice concentration image and MODIS image of the Bering Sea observed on March 19, 2016.

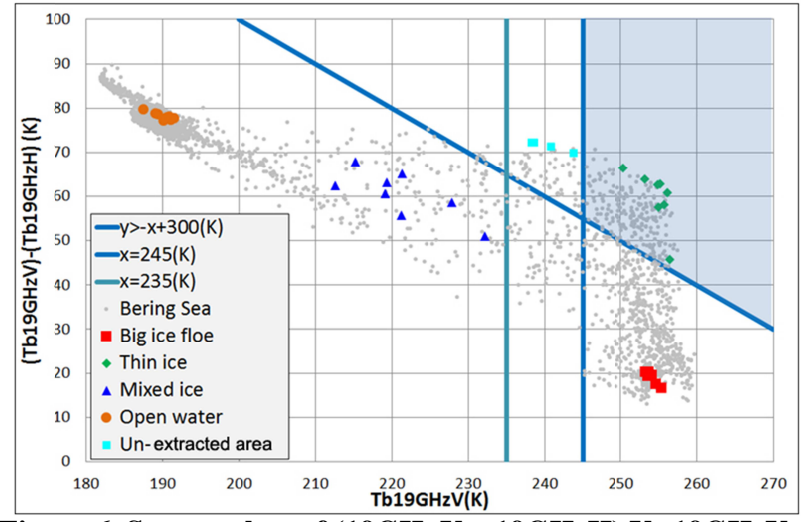

Figure 6. Scatter plots of (19GHzV - 19GHzH) Vs $19 \mathrm{GHzV}$ Polarization (Bering Sea, Mar. 19, 2016)

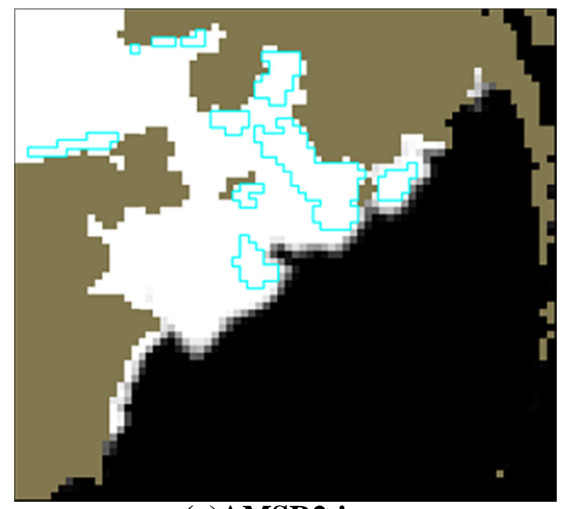

(a)AMSR2 image

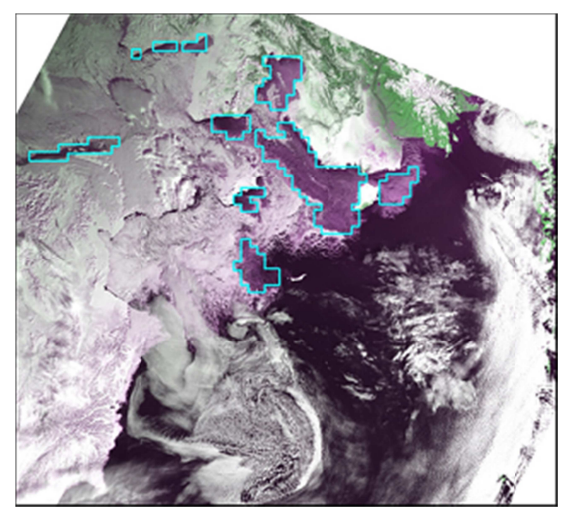

(b) MODIS image

Figure 7. Thin ice area extraction result (Cyan: extracted area) (Bering Sea, Feb. 10, 2014) 


\subsection{Gulf of St. Lawrence}

Figure 8 show the scatter plot of AMSR2 19GHz V versus $19 \mathrm{GHz}(\mathrm{V}-\mathrm{H})$ of the Gulf of St. Lawrence observed on March 1, 2015. The distribution of the data also suggests the possibility of applying the same algorithm to the Gulf of St. Lawrence. Just same with Bering Sea, the parameter T1 of equation (1) was changed from $245 \mathrm{~K}$ to $235 \mathrm{~K}$. No change to the parameter $\mathrm{T} 2=300 \mathrm{~K}$. Figure 9 show the extracted thin ice areas overlaid on the AMSR2 sea ice concentration image and MODIS image of the Bering Sea observed on March 1, 2015.

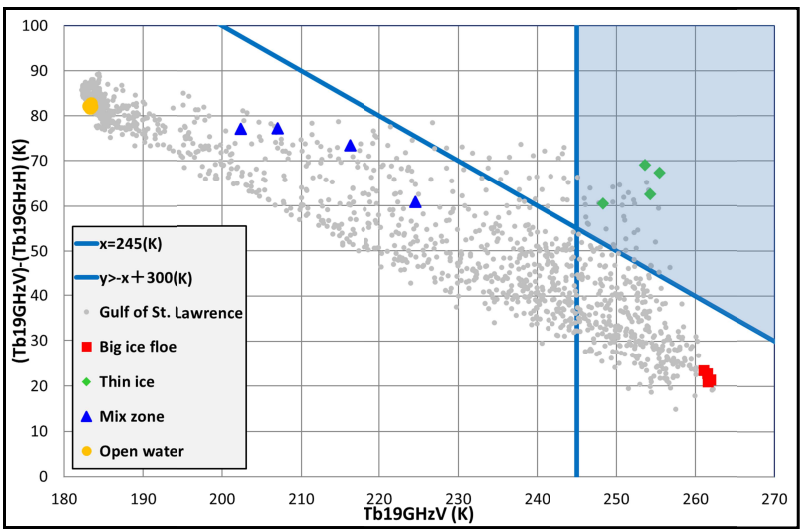

Figure 8. Scatter plots of $(19 \mathrm{GHzV}-19 \mathrm{GHzH}) \mathrm{Vs} 19 \mathrm{GHzV}$ Polarization (Gulf of St. Lawrence, Mar. 1, 2015)

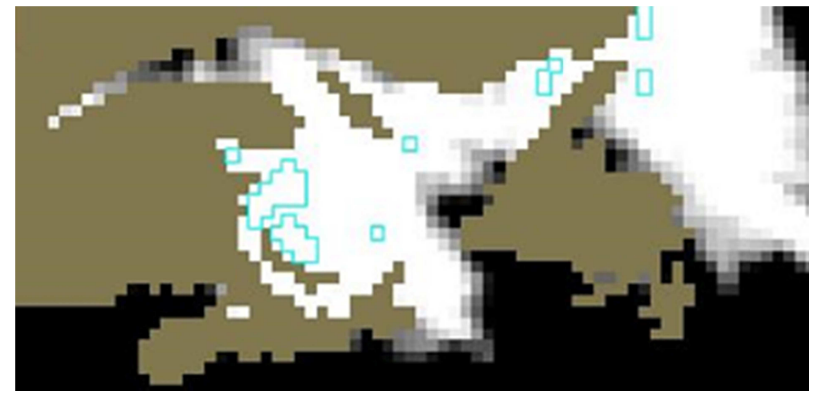

(a)AMSR2 image

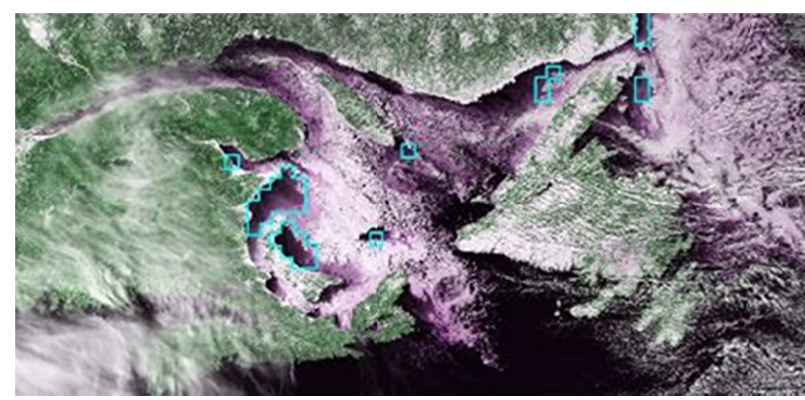

(b) MODIS image

Figure 9. Thin ice area extraction result (Cyan: extracted area) (Gulf of St. Lawrence, Mar. 1, 2015)

\section{CONCLUSION}

In this study, authors have applied the AMSR2 Thin Ice Algorithm which was originally developed for the Sea of Okhotsk also to the Bering Sea and the Gulf of St. Laurence. The extracted thin sea ice areas were validated by comparing with simultaneously collected MODIS images. The authors have analyzed around 10 scenes for the Sea of Okhotsk, the Bering Sea and the Gulf of St. Laurence. The most of the thin ice areas identified in MODIS images were well extracted from AMSR2 data by applying the algorithm. The result suggests that some tuning of the parameters may improve the accuracy of the algorithm when applying the algorithm to the other sea ice zones of the Northern Hemisphere. JAXA has decided to produce the thin ice product from AMSR2 data using the Thin Ice Algorithm as the research prodluct of AMSR2.

\section{ACKNOWLEDGEMENTS}

This study was supported by JAXA under the framework of GCOM-W Project. The authors would like to thank JAXA for their kind support.

\section{REFERENCES}

Comiso, J., 2012, Large Decadal Decline of the Arctic Multiyear Ice Cover, Journal of Cllimate, Vol. 25, pp.1176-1193 JAXA, 2012, Arctic Sea Ice Observation Data Analysis Results, Press Release, http://global.jaxa.jp/press/2012/08/20120825_ arctic_sea_e.html.

NSIDC, 2018, Arctic sea ice maximum at second lowest in the satellite record, http://nsidc.org/arcticseaicenews/

IPCC. 2014. "Summary for Policymakers." In Climate Change 2013: The Physical Basis. Contribution of Working Group I to the Fifth Assessment Report of the Intergovernmental Panel on Climate Change, edited by T.F. Stocker, D. Qin, G.K. Plattner, et al., Cambridge: Cambridge University Press.

Cavalieri, D. J. and P. Gloersen, 1984, Determination of sea ice parameters with the NIMBUS 7 SMMR, J. Geophys. Res., Vol.89, pp.5355-5369.

Comiso, J. C., 1995 ,SSM/I Sea Ice Concentrations Using the Bootstrap Algorithm", NASA Reference Publication 1380, Maryland, NASA Center for AeroSpace Information.

Svendsen, E., C. Matzler \& T. C. Grenfell, 1987, A model for retrieving total sea ice concentration from a spaceborne dualpolarized passive microwave instrument operating near $90 \mathrm{GHz}$, International Journal of Remote Sensing, Vol.8, No.10, pp.1479-1487

Maykut, G. A., 1978, Energy exchange over young sea ice in the central arctic, JGR, Vol.83, pp.3646-3658

Tateyama K., H. Enomoto,, T. Tioyota. and S. Uto, 2002, Sea ice thickness estimated from passive microwave radiometers, Polar Meteorol. Glaciol., National Institute of Polar Research, Vol. 16, pp.15-31.

Martin, S. and R. Drucker, 2005, Improvements in the estimates of ice thickness and production in the Chukchi Sea polynyas derived from AMSR-E, GRL, Voll. 32, L05505

Tamura T., K. I. Ohshima, T. Markus, D. J. Cavalieri, S. Nihashi, N. Hirasawa, 2007, Estimation of Thin Ice Thickness and Detection of Fast Ice from SSM/I Data in the Antarctic Ocean, Journal of Atmospheric and Oceanic Technology, Vol. 24, pp.1757-1772.

Cho, K., Y. Mochizuki, Y. Yoshida, 2012, Thin ice area extraction using AMSR-E data in the Sea of Okhotsk, Proceedings of the 33rd Asian Conference on Remote Sensing, TS-E6-3, pp.1-6. 
Tokutsu Y., K. Cho, 2014, Thin Ice Area Extraction Algorithm Using AMSR2 Data for the Sea of Okhotsk, Proceedings of the 35th Asian Conference on Remote Sensing, OS-101, pp.1-6.

Sato, Y., K. Naoki, K. Cho, A Study on Extracting the Trend of Then Ice Distribution in the Sea of Okhotsk Using ASMR-E and AMSR2 Data, Proceedings of the 36th Asian Conference on Remote Sensing, TUP1.49, pp.1-6. October 2015.

Cho K., Y. Mochiduki, Y. Yoshida, M. Nakayama, K. Naoki, C. F. Chen, 2011, Thin ice thickness monitoring with FORMOSAT-2 RSI data, Proceedings of the 32nd Asian Conference on Remote Sensing, TS1-2, pp.1-8

Cho K., Y. Mochizuki, Y. Yoshida, H. Shimoda and C. F. CHEN, 2012, A study on extracting thin sea ice area from space, International Archives of the Photogrammetry, Remote Sensing and Spatial Information Sciences, Vol. XXXIX-B8, pp.561-566. Comiso, J. C., 2009, Enhanced Sea Ice Concentrations and Ice Extent from AMSR-E Data, Journal of the Remote Sensing Society of Japan, Vol.29, No.1, pp.199-215.

Miyao, K., K. Naoki, K. Cho, Upgrading thin ice area extraction algorithm using AMSR2 data, Proceedings of the 39th Asian Conference on Remote Sensing, ABA469, pp.1-10. October 2018.

NASA, 2012, https://atrain.nasa.gov/ 